\title{
Leadership skills for nursing unit managers to decrease intention to leave
}

\author{
This article was published in the following Dove Press journal: \\ Nursing: Research and Reviews \\ 21 May 2015 \\ Number of times this article has been viewed
}

\author{
Michael A Roche' \\ Christine Duffield ${ }^{1,2}$ \\ Sofia Dimitrelis' \\ Belinda Frew' \\ 'Centre for Health Services \\ Management, Faculty of Health, \\ University of Technology, Sydney, \\ NSW, ${ }^{2}$ Clinical Nursing and Midwifery \\ Research Centre, School of Nursing \\ and Midwifery, Edith Cowan \\ University, Joondalup, WA, Australia
}

Correspondence: Christine Duffield Centre for Health Services Management, Faculty of Health, University of Technology, PO Box 123, Broadway, Sydney, NSW 2007, Australia

Tel +6I 29514483 I

Fax $+6 \mid 2$ 95।4 4835

Email christine.duffield@uts.edu.au
Aim: To examine specific elements of nursing leadership linked to intention to leave, in public acute care hospitals.

Background: Nurse turnover is a global issue receiving widespread attention due to prolonged and projected workforce shortages. Nurse management and leadership qualities have been associated with intention to leave and turnover of nurses. The role of the nurse unit managers in the retention of nurses is becoming increasingly important, particularly because of their strong influence on the quality and stability of the work environment.

Methods: Data were collected from 62 medical, surgical, and mixed units across eleven public acute care hospitals in three Australian states (September 2008 to August 2010). A total of 1,673 nurses completed a nurse survey that included measures of intention to leave and leadership aspects of the practice environment. Analyses explored specific leadership characteristics that were associated with turnover intent.

Results: The role of nursing unit managers was confirmed to be a major factor in nurses' intention to remain or leave their current workplace. Nurses valued "human" skills more highly than other leadership characteristics, including their manager's connection with nurses' concerns, clarity, participation in decisions, and encouragement.

Conclusion: Strong leadership qualities in the nursing unit manager have been associated with greater job satisfaction, reduced turnover intention among nursing staff, and improved patient outcomes. Nurse leaders need to be supported in an effort to retain nurses given ongoing workforce issues and to ensure high-quality patient care.

Keywords: nurse managers, leadership, work environment, turnover, retention

\section{Introduction and background}

Australia is expected to face a shortfall of as many as 109,000 nurses (27\%) by 2025, which will impact significantly on future staffing levels and the capacity of the health care system to meet patient demands. Not surprisingly, this projected shortage has focused greater attention on retention of the existing nurse workforce, which could decrease the shortage to approximately $20,000 .{ }^{1}$ Much has been written about the leadership role of nursing unit managers (NUMs) in ensuring a positive work environment, which has been linked to nurse retention. ${ }^{2}$ Indeed, NUM leadership, as measured by the leadership scale in the Practice Environment Scale of the Nursing Work Index (PES) ${ }^{3}$ and the Shortell Leadership Scale in aggregate, is strongly associated with retention. ${ }^{4}$ However, no published studies have examined the relationship between the individual items in these two scales and intention to leave. The aim of this paper is to explore specific elements of nursing leadership in public acute care hospitals that have been linked to intention to leave. 
Over the past few years in Australia, significant changes to the structure of the health care industry have led to changes in the role of $\mathrm{NUMs}^{5,6}$ from a predominantly clinical position providing clinical leadership ${ }^{7,8}$ to a more contemporary role requiring managerial, leadership, and clinical skills., ${ }^{2,9}$ Now, NUMs primarily perform general management activities (64\%) such as staff management and budgeting, with only $16 \%$ of tasks being patient focused. ${ }^{10}$ As a result of this shift in responsibilities, some have adopted the position that leading a nursing unit does not require a nurse. ${ }^{11}$ This view emanates from the public management literature, ${ }^{12,13}$ which suggests that anyone can manage any business ${ }^{11,12}$ and overlooks the clinical realities that NUMs face daily. Instability in staffing factors (turnover, high part-time rates, poor mix of staff) and instability in patient factors (high bed occupancy and unplanned admissions) increase the complexity of unit management and impact negatively on patients' morbidity and mortality. ${ }^{14}$ Managing this complexity requires leadership and an understanding of nursing work. ${ }^{15}$

This change in role of frontline managers has, to some extent, coincided with high rates of executive nurse turnover, ${ }^{16}$ which result in a lack of/change in direction for the NUM, reduced morale, ${ }^{17}$ and diminished organizational commitment. ${ }^{6}$ More importantly, dissatisfaction and disengagement with the change process result in higher nurse turnover. ${ }^{16}$ Data collected in Australia show that the average turnover rates during the recent global financial crises was $15.1 \%$ (ranging from $12.6 \%$ in NSW to $16.7 \%$ in WA), at a cost per registered nurse of AUD49,255. ${ }^{18}$ Understanding the leadership skills required of NUMs to minimize this loss of staff and human capital is critical.

A wide range of environmental and personal factors have been shown to influence nurse turnover. ${ }^{19-21}$ Studies of acute care settings have found that some environmental factors significantly associated with intent to leave are lack of communication with doctors, poor managerial leadership, little participation in hospital affairs, unsupportive work environment, lack of developmental opportunities, inadequate pay, poor work-life balance, and excessive work pressure. ${ }^{22-24}$ Personal factors linked with intent to leave include older age, low professional status, burnout, and lack of goal internalization..$^{22,25,26}$

Both theoretical and empirical works support using nurses' intention to leave as a proxy construct for actual turnover. "Reasoned action" theory describes decisions about human behavior, such as the decision to leave one's job, as a weighted function of individual intentions and societal pressures. ${ }^{27}$ Other theoretical models consider intention to leave as a cognitive step taken in conjunction with assessing alternative options and current job embeddedness. ${ }^{28}$ Providing an empirical basis for connection between intention to leave and actual turnover, a study of 365 full-time nurses at four US hospitals found that anticipated turnover predicted actual turnover with a fairly high rate of accuracy $(73 \%-76 \%){ }^{29}$

A literature review by Cowden et al identified 23 highand medium-quality manuscripts examining the relationship between nurse manager leadership and intention to stay. ${ }^{20}$ The instruments most frequently used to detect leadership qualities were the Multifactor Leadership Questionnaire (four studies) and the Nurse Working Index (three studies). Eighteen of the studies detected a positive relationship, six found a negative relationship, and five found no significant relationship. ${ }^{20}$ Several studies on this topic have been published since that review. Carlos Do Rego Furtado et al surveyed 266 nurses in a Portuguese hospital using the Leadership Effectiveness and Adaptability Description (LEAD) measure. ${ }^{30}$ They found that persuading and sharing are the leadership components most negatively associated with retention. ${ }^{30}$ A second study of 342 recent nursing graduates found that nurse manager leadership, which was measured using the Multifactor Leadership Questionnaire, was associated with higher job satisfaction and thus lower career abandonment intent. ${ }^{31}$ Finally, Duffield et al used the leadership domain of the Revised Nursing Work Index to show that nurse manager leadership, in aggregate, is a significant predictor of job satisfaction and intention to leave. $^{2}$

The PES and the Shortell Leadership Scale hold particular promise to reveal substantive findings about the relationship between NUMs and staff nurse intent to leave, as they both contain subscales with questions specifically about nurse leadership. Both are strongly based in theoretical concepts, validated, and easy to administer., ${ }^{3,4}$ The PES has been used to examine nurse staffing ${ }^{32}$ and nurse outcomes such as nurse burnout, ${ }^{33,34}$ emotional exhaustion, ${ }^{35}$ job satisfaction, ${ }^{36}$ and intent to leave. ${ }^{37,38}$ The Shortell Leadership Scale is also frequently relied upon in the literature. ${ }^{39-42}$ Although many studies have examined the relationship between different aspects of nurse manager leadership and staff nurses' intent to leave or a related outcome, none have investigated which of the individual items of the PES or the Shortell Leadership Scale are most strongly associated with intent to leave, a gap filled by this study. 


\section{Methods}

This paper reports a secondary analysis of data collected for a larger study that has investigated nurses' views of turnover ${ }^{43}$ and explored the rates and costs of nursing turnover in Australia. ${ }^{14,18}$

\section{Sample and settings}

Data were collected in eleven public acute care hospitals across three Australian states from September 2008 to August 2010. A random selection of 62 medical, surgical, and mixed medical/rehabilitation nursing units were included in the study. Data were collected from each ward in two 3-month periods separated by 12 months. Data collected included a nurse survey, patient outcomes, and a unit profile that measured unit turnover and turnover costs. In order to address the aim described in the Introduction and background section, only subset of data from the nurse survey is reported here. All nurses on each ward were asked to complete the nurse survey during each data collection period. Across the 62 wards, an overall response rate of $44.4 \%(n=1,673)$ was achieved. The survey was voluntary and anonymous, and the study was approved by seven Human Research Ethics Committees representing the participating health services and the university.

\section{Instruments}

The nurse survey included a range of demographic items (age, sex, and experience as a nurse) and other data not reported here. ${ }^{14}$ Nurses' intention to leave their current position was captured in a single question with a dichotomous response: not intending to leave or intending to leave within 12 months. Two instruments collected data on aspects of nursing leadership: $\mathrm{PES}^{3}$ and the leadership scale from Shortell's ICU NursePhysician Questionnaire. ${ }^{4}$

\section{PES}

The PES is currently the most widely used tool to assess the quality of the nursing work environment. ${ }^{44}$ It consists of 31 items that measure five domains: nurse-doctor relationships; nurse manager ability, leadership, and support of nurses; foundations for quality of care; participation in hospital affairs; and staffing and resource adequacy., ${ }^{3,32}$ The PES has been used in a wide variety of nursing studies and has demonstrated validity and generalizability ${ }^{45}$ Each item is scored on a 4-point scale (1-4) with higher scores showing a stronger presence of that item. Subscales are calculated as a mean of the relevant items. In this study, only the nurse leadership domain is explored.

\section{Shortell Leadership Scale}

Eight items from the ICU Nurse-Physician Questionnaire, focusing on nursing leadership, were used in this study. ${ }^{4}$ Example items include the following: "This unit nursing leadership emphasizes standards of excellence to the staff" and "This unit nursing leadership is sufficiently sensitive to the different needs of unit members". The original scale is a 47-item tool used to measure the quality of communication, co-ordination, and relations between nurses and physicians. ${ }^{36}$ It was originally designed for intensive care unit work environments but is considered suitable for other workplace settings. ${ }^{36}$ Each of the eight items is scored on a 4-point Likert scale, with the mean of these items providing a view of leadership in the range of $1-4 .^{4}$

\section{Analysis}

Data were analyzed using Stata version $12 .{ }^{46}$ Descriptive analyses were first undertaken in order to provide an overview of the nature of the sample. Tests of difference ( $t$-test) and univariate logistic regression models on intent to leave were undertaken in order to confirm the expected association between each of the leadership scales and the dependent variable. Subsequently, factor analysis (principal axis factoring) was performed to determine which of the specific items loaded most strongly on the leadership domain.

\section{Results}

The total number of responses to the survey was 1,673 (response rate $44.4 \%$ ), with 1,635 providing a complete response to the items examined here (Table 1). The average

Table I Sample and leadership scale characteristics

\begin{tabular}{|c|c|c|c|c|c|}
\hline & $\begin{array}{l}\text { Intending to } \\
\text { leave, mean (SD) }\end{array}$ & $\begin{array}{l}\text { Not intending to } \\
\text { leave, mean (SD) }\end{array}$ & $t(d f)$ & $P$-value & $\begin{array}{l}\text { Overall } \\
\text { mean (SD) }\end{array}$ \\
\hline $\begin{array}{l}\text { Nurse manager leadership } \\
\text { and support (PES) }\end{array}$ & $2.71(0.719)$ & $2.95(0.605)$ & $5.78 \mid(510.45)$ & $<0.01$ & $2.89(0.640)$ \\
\hline Shortell Leadership Scale & $2.76(0.559)$ & $2.94(0.574)$ & $5.09(586)$ & $<0.01$ & $2.90(0.575)$ \\
\hline $\mathrm{N}$ & $366(22.4 \%)$ & I,269 (77.6\%) & & & 1,635 \\
\hline
\end{tabular}

Abbreviations: SD, standard deviation; $d f$, degrees of freedom; PES, Practice Environment Scale. 
age of respondents was 39.2 years, the average experience 11.7 years, and the majority were female $(n=1,482,90.6 \%)$. Most ( $n=1,316,80.5 \%)$ were registered nurses, employed full time $(n=985,60.3 \%)$, and on permanent contracts $(n=1,493$, $91.3 \%$ ). Over three quarters of participants indicated that they were not intending to leave their current position within the next 12 months $(n=1,269,77.6 \%)$. The overall mean score for the PES leadership scale was in the positive range as described by Lake and Friese ${ }^{32}$ but with a statistically significant difference between those who intended to leave and those who did not. Similarly, differences were found between the groups on the Shortell Leadership Scale.

Separate univariate logistic regression models were conducted on nurses' intent to leave: one with each of the scales as the explanatory variable. Each scale was found to be a negative predictor. For each point increase in the PES leadership scale, there was a $44 \%$ decrease in the odds of intending to leave (Table 2). The Shortell Leadership Scale showed a similar effect, with a potential impact, for both scales, of up to a $53 \%$ decrease in the odds of intending to leave. As the purpose of this paper was to explore specific leadership items that linked to turnover intention rather than to determine the most predictive of these scales, a regression analysis that used both scales as explanatory variables was not performed. Rather, a factor analysis of each scale was undertaken to explore which of the individual items loaded most strongly on their respective scales.

Principal axis factoring of the five items in the PES domain nurse manager ability, leadership, and support of nurses indicated that all items loaded in the very good range, at over 0.6 (Table 3). ${ }^{47}$ The perceived leadership ability of nurses' immediate manager was the strongest item at 0.720 , substantially more than the other four items. In decreasing order of loading were two items regarding manager's support of clinical nurses, followed by the leader's attitude toward learning from mistakes and perceived praise and recognition.

With regard to the eight items of the Shortell Leadership Scale (Table 4), the standout item was the manager's connection with nurses' concerns. Clarity, participation in decisions, and encouragement were also regarded as important,

Table 2 Logistic regression models on intent to leave

\begin{tabular}{llll}
\hline Scale & OR (SE) & $\mathbf{9 5 \% ~ C l ~}$ & P-value \\
\hline $\begin{array}{l}\text { Nurse manager leadership } \\
\text { and support (PES) }\end{array}$ & $0.56(0.052)$ & $0.47-0.68$ & $<0.01$ \\
$\begin{array}{l}\text { Shortell Leadership } \\
\text { Scale }\end{array}$ & $0.59(0.063)$ & $0.48-0.72$ & $<0.0$ I \\
\hline
\end{tabular}

Abbreviations: OR, odds ratio; $\mathrm{SE}$, standard error; $\mathrm{Cl}$, confidence interval; $\mathrm{PES}$, Practice Environment Scale.
Table 3 Factor analysis of "nurse manager ability, leadership, and support of nurses" (PES)

\begin{tabular}{ll}
\hline Item & Loading \\
\hline $\begin{array}{l}\text { A nurse manager or immediate supervisor who is a good } \\
\text { manager and leader }\end{array}$ & 0.720 \\
A supervisory staff who is supportive of the nurses & 0.683 \\
A nurse manager or supervisor who backs up the nursing & 0.669 \\
staff in decision making, even if the conflict is with a physician & \\
$\begin{array}{l}\text { Supervisors use mistakes as learning opportunities, } \\
\text { not criticism }\end{array}$ & 0.656 \\
Praise and recognition for a job well done & 0.649 \\
\hline
\end{tabular}

Notes: Principal axis factoring: Kaiser-Meyer-Olkin 0.840; Bartlett's test 2,412.489 (I0); $P<0.01$; \% of variance 47.549; Cronbach's alpha 0.82 .

Abbreviation: PES, Practice Environment Scale.

while high standards of care were slightly lower (although above 0.5 ). Most items loaded in the good-to-very good range, ${ }^{47}$ although the loading for the manager's problemsolving skills was in the poor range.

\section{Discussion}

This analysis supports the growing body of work that finds that the role of NUMs is a major factor in nurses' decisions about whether or not to remain in their current workplace. More specifically, the results presented here provide an indication of some of the leadership skills that nurses seeking to undertake a management position must possess. That is, while nurse managers must be adequately prepared to manage a unit's staffing and finances, it is the "human" skills most valued by nurses in their leaders. As workforce shortages are projected to continue, the need to develop and maintain nurse managers' skills associated with retention will become even more critical.

Table 4 Factor analysis of Shortell Leadership Scale

\begin{tabular}{ll}
\hline Item & Loading \\
\hline $\begin{array}{l}\text { This unit nursing leadership is in touch with nurse } \\
\text { perceptions and concerns }\end{array}$ & 0.815 \\
$\begin{array}{l}\text { This unit's nurses are clear where they stand with } \\
\text { the unit nursing leadership }\end{array}$ & 0.773 \\
$\begin{array}{l}\text { This unit nursing leadership does not make decisions } \\
\text { without input from unit nurses }\end{array}$ & 0.738 \\
$\begin{array}{l}\text { This unit nursing leadership encourages nurses } \\
\text { in taking initiative }\end{array}$ & 0.679 \\
$\begin{array}{l}\text { This unit nursing leadership is sufficiently sensitive to the } \\
\text { different needs of unit members }\end{array}$ & 0.643 \\
$\begin{array}{l}\text { This unit nursing leadership makes it clear what it expects } \\
\text { from members }\end{array}$ & 0.618 \\
$\begin{array}{l}\text { This unit nursing leadership emphasizes standards } \\
\text { of excellence to the staff }\end{array}$ & 0.585 \\
$\begin{array}{l}\text { This unit nursing leadership effectively adapts } \\
\text { its problem-solving style to changing circumstances }\end{array}$ & 0.379 \\
\hline $\begin{array}{l}\text { Note Prnipa } \\
\text { nas }\end{array}$
\end{tabular}

Notes: Principal axis factoring: Kaiser-Meyer-Olkin 0.871; Bartlett's test 5,207.062 (28); $P<0.01$; \% of variance 44.36 ; Cronbach's alpha 0.86 . 
Previous research has identified the significance of communication and conflict resolution skills, collaborative and participative decision making, accessibility, recognition and constructive feedback, and the leadership qualities found to be important in the present study. ${ }^{2,9,48}$ We found that nurses perceive more positive leadership when the NUM engages with nursing staff, provides support and motivation, is sensitive to their needs, and facilitates professional development. This contrasts with those skills and attributes that are more traditionally associated with management such as supervising, controlling, or directing. ${ }^{49}$ It is challenging but important for NUMs to provide support and demonstrate leadership during periods of change as the associated insecurity that accompanies it can increase workplace stress and reduce mental wellbeing, especially among newer and younger nurses. ${ }^{50,51}$

However, new NUMs do not always have the skills necessary for the role. Traditionally, these managers have been selected based on clinical skills and level of seniority, with or without a formal qualification in management. ${ }^{52,53}$ Once appointed to managerial roles, many experience role ambiguity and struggle with the level of skill required. ${ }^{54}$ Further, they often have limited opportunities to acquire these skills "on the job" ${ }^{2,55}$ and may therefore take months to transition into the position, affecting productivity, nurse satisfaction, and patient outcomes. ${ }^{52,55}$ In order to become accomplished leaders and managers, attention must be paid to the appropriate selection of candidates, mentoring, organizational support, and educational qualifications. Consideration may also be given to the formation of a specific professional organization for frontline managers.

New NUMs require the support of senior managers, and of the organization as a whole, in their transition to this role, a difficult task when executive turnover has been shown to be high. ${ }^{56,57} \mathrm{~A}$ key aspect of organizational support is ensuring clarity in the aims and functions of the managers as some have reported a lack of authority and autonomy when their role is not clear. ${ }^{58}$ This corresponds to the role ambiguity described in the previous paragraph and possibly also links to a lack of academic qualifications, leaving nurse managers feeling less confident in their own abilities. ${ }^{59}$ One strategy suggested to address these issues and to improve leadership competencies is strategic succession planning. ${ }^{52,55}$ Providing mentoring from senior managers may offer role clarity as well as providing support. ${ }^{60}$

Effective succession planning also facilitates the retention of organizational knowledge ${ }^{61}$ and fundamentally, permits the identification of potential leaders before they are formally in a management role, providing the time needed for mentoring and formal education for leadership development. ${ }^{62}$ That is, clinical skills and seniority may not be the most appropriate criteria on which to judge suitability for the role. Indeed, if many new managers are experiencing role ambiguity, it suggests that there is significant improvement to be made in selecting those candidates with effective leadership skills or those who are able to readily develop them. ${ }^{54}$

In accordance with the findings of this study, educational programs for these candidates should not only focus on management skills but must also instill the essential people skills for appropriate leadership. However, Titzer et al note that current approaches to on-the-job training and didactic education often create ineffective leaders. ${ }^{55}$ In the US, organizations such as the American Organization of Nurse Executives established in 1967 aim to shape health care through nursing leadership by supporting nurse leaders in management, leadership, education, and professional development, and by influencing public policy and legislation. ${ }^{63}$ Other US organizations committed to leadership initiatives include the American Academy of Nursing. ${ }^{64}$ Similarly, in the UK, the National Health Service Leadership Academy runs programs (eg, Top Leaders program, Ready Now program, Frontline Nursing and Midwifery program, Senior Operational Leaders program) for different levels of leadership responsibilities and experience with a focus on developing leadership skills (eg, greater influence and impact, strategic, stronger voice) ${ }^{65}$ The Royal College of Nursing Clinical Leadership Program also provides a framework for first-line nurse managers to develop skills in leadership and management. ${ }^{66}$ It is timely for Australia to follow in this direction to ensure that nurse leaders are able to drive policy change and health care reform for improved quality of health care and patient outcomes. ${ }^{66}$

Further, organizations must ensure not only that nurse managers have the skills to effectively lead and support their staff but also that change processes do not diminish their authority and influence within the organization. For example, recent work in the US found that nurses derived support from the wider organization rather than directly from unit managers ${ }^{67}$ Those researchers suggested that this perception of unit managers may be linked to organizational reforms and subsequent diminishment of nurse manager authority and influence. If nurse managers are to support and retain staff, the potential impact of organizational change must be considered and addressed.

\section{Limitations}

This study was not intended to repeat analyses that have regressed environmental and organizational factors on 
outcomes such as intent to leave or job satisfaction. The analysis is intended to identify and explore key aspects of nursing leadership derived from the items of the PES and Shortell Leadership Scale.

The univariate regression models undertaken on intent to leave did not account for the known complexity of the nursing practice and organizational environment. Their purpose here was to confirm the relationship between leadership and the outcome variable, not to explore the strength of this factor, as has been undertaken in many other studies. This confirmation then permitted confirmatory factor analysis to identify those items that loaded most strongly, addressing the aim of the paper.

The response rate in this study was $44.4 \%$, consistent with survey responses in other studies. ${ }^{68}$ Participation was voluntary, so there was no opportunity to compare participants to those who did not participate. This does limit the generalizability of the findings.

\section{Conclusion}

This study supports previous findings that NUMs play an important role in the operation and well-being of a nursing unit. When the leadership on a ward is perceived by staff to be strong, consistent, and effective, it is associated with greater job satisfaction and reduced turnover intention among nursing staff, ${ }^{17}$ and is also linked to increased satisfaction and reduced negative outcomes in patients. ${ }^{69}$ The central role of the nurse manager in retention is important to consider regardless of the influence of external factors linked to variations in retention rates, such as the number of employment options. ${ }^{24,70}$ These factors will fluctuate and in order to address them over the long term, nurse manager's focus on the development and maintenance of positive, healthy work environments, that foster nurse fulfillment and build workplace commitment, would offer better results for the health care industry.

As a key component, and driver, of positive work environments, ${ }^{31,38}$ development and support of frontline nursing leadership must be a priority issue for health services in order to address ongoing workforce issues and of course in the interest of high-quality patient care. Pegram et $\mathrm{al}^{71}$ note that the lack of preparation for ward leadership roles reflects the lack of attention made by decision makers to the importance of management at the ward level. They conclude that further research is required to determine what unit managers do and the skills they need. This study contributes to that discussion and has clarified some of the essential leadership qualities that are essential in these positions.

\section{Acknowledgments}

This paper is part of an international project to examine the cost of nurse turnover and the impact of turnover on patient safety and nurse health and safety outcomes. Co-principal investigators are Professor Linda O'Brien Pallas (University of Toronto, Toronto, ON, Canada) and Dr Judith Shamian (Victorian Order of Nurses, Ottawa, ON, Canada). Team members include Dr Heather Laschinger (University of Western Ontario, London, ON, Canada), Dr Pat Griffin (Health Canada, Ottawa, ON, Canada), Professor James Buchan (Queen Margaret University College, Edinburgh, UK), Dr Patricia Stone (Columbia University, New York, NY, USA), and Associate Professor Nicola North (University of Auckland, Auckland, New Zealand).

This research was funded by an Australian Research Council Linkage Grant (LP0774836). Thanks go to the following organizations that participated: Australian Capital Territory Health, Northern Sydney Central Coast Area Health Service, and Western Australia Health. Thanks also go to the participating hospitals: the Canberra Hospital, Hornsby Ku-ring-gai Hospital, Royal North Shore Hospital, Wyong Hospital, Sir Charles Gairdner Hospital, Bentley Hospital, Osborne Park Hospital, Fremantle Hospital, Royal Perth Hospital, Armadale-Kelmscott Hospital, and Swan-Kalamunda Hospital.

A special thank you also goes to the research assistants who worked on this project: Dr Helen Stasa, Ms Nicole Blay, and Ms Sarah Friedman (University of Technology, Sydney).

\section{Disclosure}

The authors declare no potential conflicts of interest with respect to the research, authorship, and/or publication of this article.

\section{References}

1. Health Workforce Australia. Health Workforce 2025 - Doctors, Nurses and Midwives - Volume 1. Sydney: HWA; 2012.

2. Duffield C, Roche MA, Blay N, Stasa H. Nursing unit managers, staff retention and the work environment. $J$ Clin Nurs. 2010;20(1-2): 23-33.

3. Lake ET. Development of the practice environment scale of the nursing work index. Res Nurs Health. 2002;25(3):176-188.

4. Shortell SM, Rousseau DM, Gillies RR, Devers KJ, Simons TL. Organizational assessment in intensive care units (ICUs): construct development, reliability, and validity of the ICU nurse-physician questionnaire. Med Care. 1991;29:709-726.

5. Duffield C, Roche MA, Blay N, Thoms D, Stasa H. The consequences of executive turnover. J Res Nurs. 2011;16(6):503-514.

6. Duffield C, Kearin M, Johnston J, Leonard J. The impact of hospital structure and restructuring on the nursing workforce. Aust $J$ Adv Nurs. 2007;24(4):42. 
7. Duffield C, Franks H. The role and preparation of first-line nurse managers in Australia: where are we going and how do we get there? J Nurs Manag. 2001;9(2):87-91.

8. Duffield C, Moran P, Beutel J, et al. Profile of first-line nurse managers in New South Wales, Australia, in the 1990s. J Adv Nurs. 2001;36(6): 785-793.

9. Schmalenberg C, Kramer M. Nurse manager support: how do staff nurses define it? Crit Care Nurse. 2009;29(4):61-69.

10. NSW Department of Health. Take the Lead: Strengthening the Nursing/ Midwifery Unit Manager Role Across NSW. North Sydney: NSW; 2009.

11. Riddell S. Why do nurses believe they are management material? Nurs Times. 2011;107(46):11.

12. Baumgartner RJ. Generic management: a basis for implementing sustainable business management. In: 14th International Conference on Management of Technology; 2005; Vienna, Austria.

13. Newman S, Lawler J. Managing health care under New Public Management A Sisyphean challenge for nursing. J Sociol. 2009;45(4): 419-432.

14. Duffield C, Roche MA, Dimitrelis S, Homer C, Buchan J. Instability in patient and nurse characteristics, unit complexity, and patient and system outcomes. JAdv Nurs. Epub 2014 Dec 16.

15. Cziraki K, McKey C, Peachey G, Baxter P, Flaherty B. Factors that facilitate registered nurses in their first-line nurse manager role. J Nurs Manag. 2014;22(8):1005-1014.

16. Jones CB. Revisiting nurse turnover costs: adjusting for inflation J Nurs Adm. 2008;38(1):11-18.

17. Duffield C, Roche MA, O’Brien-Pallas L, Catling-Paull C. The implications of staff 'churn' for nurse managers, staff, and patients. Nurs Econ 2009;27(2):103-110.

18. Roche MA, Duffield C, Homer C, Buchan J, Dimitrelis S. The rate and cost of nurse turnover in Australia. Collegian. Epub 2014 Jun 10.

19. Flinkman M, Leino-Kilpi H, Salantera S. Nurses' intention to leave the profession: integrative review. J Adv Nurs. 2010;66(7): 1422-1434.

20. Cowden T, Cummings GG, Profetto-McGrath J. Leadership practices and staff nurses' intent to stay: a systematic review. J Nurs Manag. 2011;19(4):461-477.

21. Coomber B, Barriball KL. Impact of job satisfaction components on intent to leave and turnover for hospital-based nurses: a review of the research literature. Int J Nurs Stud. 2007;44(2):297-314.

22. Heinen MM, van Achterberg T, Schwendimann R, et al. Nurses' intention to leave their profession: a cross sectional observational study in 10 European countries. Int J Nurs Stud. 2013;50(2):174-184.

23. van der Heijden BI, Kummerling A, van Dam K, van der Schoot E, Estryn-Behar M, Hasselhorn HM. The impact of social support upon intention to leave among female nurses in Europe: secondary analysis of data from the NEXT survey. Int J Nurs Stud. 2010;47(4): 434-445.

24. Carter MR, Tourangeau AE. Staying in nursing: what factors determine whether nurses intend to remain employed? J Adv Nurs. 2012;68(7): 1589-1600.

25. Rheaume A, Clement L, Lebel N. Understanding intention to leave amongst new graduate Canadian nurses: a repeated cross sectional survey. Int J Nurs Stud. 2011;48(4):490-500.

26. Cortese CG. Predictors of the critical care nurses' intention to leave the unit, the hospital, and the nursing profession. Open J Nurs. 2012;2(3A): 311-326.

27. Fishbein M, Ajzen I. Predicting and Changing Behavior. 1st ed. UK: Psychology Press; 2009.

28. Crossley C, Bennett R, Jex SM, Burnfield JL. Development of a Global measure of job embeddedness and integration into a traditional model of voluntary turnover. J Appl Psychol. 2007;92(4): 1031-1042.

29. Lucas MD, Atwood JR, Hagaman R. Replication and validation of anticipated turnover model for urban registered nurses. Nurs Res. 1993;42(1):29-35
30. Carlos Do Rego Furtado L, Da Graca Camara Batista M, Jose Ferreira Silva F. Leadership and job satisfaction among Azorean hospital nurses: an application of the situational leadership model. J Nurs Manag. 2011;19(8):1047-1057.

31. Laschinger HKS, Leiter MP. The impact of nursing work environments on patient safety outcomes: the mediating role of burnout engagement. J Nurs Adm. 2006;36(5):259-267.

32. Lake ET, Friese CR. Variations in nursing practice environments: relation to staffing and hospital characteristics. Nurs Res. 2006;55(1): $1-9$.

33. Aiken LH, Clarke SP, Sloane DM. Hospital staffing, organization, and quality of care: cross-national findings. Nurs Outlook. 2002;50(5): 187-194.

34. O'Brien-Pallas L, Shamian J, Thomson D, et al. Work-related disability in Canadian nurses. J Nurse Scholarship. 2004;36(4):352-357.

35. Friese CR. Nurse practice environment and outcomes: implications for oncology nursing. Oncol Nurs Forum. 2005;32(4):765-772.

36. Manojlovich M. Linking the practice environment to nurses' job satisfaction through nurse-physician communication. J Nurs Scholarship. 2005;37(4):367-373.

37. Thomas-Hawkins C. Staff nurses' perceptions of the work environment in freestanding hemodialysis facilities. Nephrol Nurs J. 2003;30(4): 377-386.

38. Roche MA, Laschinger HKS, Duffield C. Testing the nursing worklife model in Canada and Australia: a multi-group comparison study. Int $J$ Nurs Stud. 2015;52(2):525-534.

39. Shortell SM, Zimmerman JE, Rousseau DM, et al. The performance of intensive care units: does good management make a difference? Med Care. 1994;32(5):508-525.

40. Scott-Cawiezell J, Schenkman M, Moore L, et al. Exploring nursing home staff's perceptions of communication and leadership to facilitate quality improvement. J Nurs Care Qual. 2004; 19(3):242-252.

41. Boyle DK, Kochinda C. Enhancing collaborative communication of nurse and physician leadership in two intensive care units. J Nurs Adm. 2004;34(2):60-70

42. Reader TW, Flin R, Mearns K, Cuthbertson BH. Interdisciplinary communication in the intensive care unit. Br J Anaesth. 2006;98(3) $347-352$.

43. Dawson A, Stasa H, Roche MA, Homer C, Duffield C. Nursing churn and turnover in Australian hospitals: nurses perceptions and suggestions for supportive strategies. BMC Nurs. 2014;13(1):11.

44. Warshawsky NE, Havens DS. Global use of the practice environment scale of the nursing work index. Nurs Res. 2011;60(1):17.

45. Parker D, Tuckett A, Eley R, Hegney D. Construct validity and reliability of the practice environment scale of the nursing work index for Queensland nurses. Int J Nurs Pract. 2010;16(4):352-358.

46. Stata [computer program]. Version 12. College Station, Texas: StataCorp; 2011.

47. Tabachnick BG, Fidell LS. Using Multivariate Statistics. 5th ed. Boston: Pearson Education, Inc.; 2007.

48. Milstead JA, Furlong E. Handbook of Nursing Leadership: Creative Skills for a Culture of Safety. Sudbury, MA: Jones and Bartlett Publishers; 2008.

49. Watson C. Assessing leadership in nurse practitioner candidates. Aus JAdv Nurs. 2008;26(1):67.

50. Adam ML, Flatau P. Job insecurity and mental health outcomes: an analysis using waves 1 and 2 of HILDA. Econ Lab Relat Rev. 2006;17(1):143-170.

51. Cheng GHL, Chan DKS. Who suffers more from job insecurity? A meta-analytic review. Appl Psychol. 2008;57(2):272-303.

52. Abraham PJ. Developing nurse leaders: a program enhancing staff nurse leadership skills and professionalism. Nurs Adm Q. 2011;35(4): 306-312.

53. Fennimore L, Wolf G. Nurse manager leadership development: leveraging the evidence and system-level support. J Nurs Adm. 2011;41(5): 204-210. 
54. McCallin AM, Frankson C. The role of the charge nurse manager: a descriptive exploratory study. J Nurs Manag. 2010;18(3):319-325.

55. Titzer J, Phillips T, Tooley S, Hall N, Shirey M. Nurse manager succession planning: synthesis of the evidence. J Nurs Manag. 2013;21(7): 971-979.

56. Townsend K, Wilkinson A, Allan C, Bamber G. Accidental, unprepared and unsupported: the ward manager's journey. Int J Human Res Manag. 2012;23(1):204-220.

57. Townsend K, Wilkinson A, Kellner A. Opening the black box in nursing work and management practice: the role of ward managers. J Nurs Manag. Epub 2013 Jul 16.

58. Duygulu S, Kublay G. Transformational leadership training programme for charge nurses. J Adv Nurs. 2011;67(3):633-642.

59. Sanford KD. The case for nursing leadership development. Healthc Financ Manage. 2011;65(3):100-104, 106.

60. Laframboise LE. Making the case for succession planning: who's on deck in your organization? Nurs Leadersh. 2011;24(2):68-79.

61. Keys Y. Looking ahead to our next generation of nurse leaders: generation X nurse managers. J Nurs Manag. 2014;22(1):97-105.

62. Carriere BK, Muise M, Cummings GG, Newburn-Cook C. Healthcare succession planning: an integrative review. J Nurs Adm. 2009;39(12): $548-555$.

63. American Organization of Nurse Executives. About AONE; 2014. Available from: http://www.aone.org/membership/about/welcome. shtml. Accessed November 6, 2014.
64. American Association of Colleges of Nursing. Links to Colleague Organizations; 2014. Available from: http://www.aacn.nche.edu/ education-resources/colleague-organizations. Accessed November 6, 2014.

65. NHS Leadership Academy. Programmes: Developing Better Leaders, Delivering Better Care; 2014. Available from: http://www. leadershipacademy.nhs.uk/programmes/. Accessed November 6, 2014.

66. Royal College of Nursing. Breaking Down Barriers, Driving up Standards: The Role of the Ward Sister and Charge Nurse. London: RCN; 2009.

67. Brunetto Y, Xerri M, Shriberg A, et al. The impact of workplace relationships on engagement, well-being, commitment and turnover for nurses in Australia and the USA. J Adv Nurs. 2013;69(12):2786-2799.

68. Baruch Y, Holtom BC. Survey response rate levels and trends in organizational research. Human Relat. 2008;61(8):1139-1160.

69. Wong CA, Cummings GG. The relationship between nursing leadership and patient outcomes: a systematic review. J Nurs Manag. 2007;15(5): 508-521.

70. Hayes LJ, O’Brien-Pallas L, Duffield C, et al. Nurse turnover: a literature review - an update. Int J Nurs Stud. 2012;49(7):887-905.

71. Pegram AM, Grainger M, Sigsworth J, While AE. Strengthening the role of the ward manager: a review of the literature. J Nurs Manag. 2014;22(6):685-696.

\section{Publish your work in this journal}

Nursing: Research and Reviews is an international, peer-reviewed, open access journal publishing original research, reports, reviews and commentaries on all aspects of nursing and patient care. These include patient education and counselling, ethics, management and organizational issues, diagnostics and prescribing, economics and

\section{Dovepress}

resource management, health outcomes, and improving patient safety in all settings. The manuscript management system is completely online and includes a very quick and fair peer-review system. Visit http://www.dovepress.com/testimonials.php to read real quotes from published authors. 